\title{
Note Taking and Note Sharing While Browsing Campaign Information
}

\author{
Scott P. Robertson \\ University of Hawaii \\ Information \& Computer \\ Sciences Department
}

\author{
Ravi Vatrapu \\ University of Hawaii \\ Information \& Computer \\ Sciences Department
}

\author{
George Abraham \\ Drexel University \\ College of Information \\ Science and Technology
}

\{ scott.robertson, vatrapu \}@ hawaii.edu, george.abraham@ischool.drexel.edu

\begin{abstract}
Participants were observed while searching and browsing the internet for campaign information in a mock-voting situation in three online note-taking conditions: No Notes, Private Notes, and Shared Notes. Note taking significantly influenced the manner in which participants browsed for information about candidates. Note taking competed for time and cognitive resources and resulted in less thorough browsing. Effects were strongest when participants thought that their notes would be seen by others. Think-aloud comments indicated that participants were more evaluative when taking notes, especially shared notes. Our results suggest that there could be design trade-offs between $e$ Democracy and e-Participation technologies.
\end{abstract}

\section{Introduction}

The internet has grown into an important political information tool. Usage by candidates and citizens in the United States has grown tremendously over the last several election cycles [1, 2]. Smith \& Rainie [3] report that $46 \%$ of Americans have used the internet to get news and information about the 2008 U.S. presidential campaign. According to Kohut [4], 24\% of Americans (42\% between the ages of 18-29) said that they used the internet "regularly" to gain campaign information.

Politicians and citizens have also begun to use a wide variety of internet tools. Just as the Howard Dean campaign gained credit for innovative use of organizational internet tools, blogs, and online referenda in 2000 [5,6], the current campaign of Barack Obama is gaining a reputation as an innovator on social networks such as MySpace and Facebook [7], although all campaigns have effectively used these social networks [8] to raise money, raise awareness, and build constituencies [see also 3,4]. Hillary Clinton used web video to announce her candidacy, and YouTube has assumed a central role in the debates for the 2008 presidential election. Evidence suggests that "wired" voters are exposed to more points of view about candidates and issues than voters who do not use the internet, and that internet users do not narrow information consumption to their own special interests [9].

Growth in use of internet-based information sources and technologies is so rapid that theory development and empirical study is lagging behind. We have argued for a "design science" approach to the study of technology-enhanced political information behavior [10-12] which involves continuous cycles of development and empirical study of information systems for e-Democracy, however in practice we are discovering that these cycles must be quite rapid. Robertson, Wania, Abraham, \& Park [12] presented data on a study of a drop-down interface to a search query engine and showed that the interface encouraged more issuebased consideration of the candidates. Here we extend our study of this interface to include an annotation component. Before discussing our study, we briefly review issues related to note taking in general and web annotation in particular.

\subsection{Note Taking and Web Annotation}

Debriefing sessions from our previous studies have often revealed a desire among browsers of political information to make point-by-point comparisons of candidates, an activity that should be enhanced by the ability to take notes. Also, participation in political blogs and candidate-centered social networking sites suggests that many web users are eager to share their thoughts about political issues with others and curious to view the thoughts of others. We therefore studied several users of our previously-designed drop-down search query interface [12] under various web annotation conditions. 
Note taking is a way to select important pieces of information from a larger set of items and transfer that information to a local "external memory" for later use. Note taking may also enhance retention or understanding by helping learners focus their attention and concentrate on important information. Note taking is common in learning situations [13] and many attempts have been made to develop annotation systems that can be used during web browsing [14]. Although note taking seems intuitively helpful, empirical studies suggest that its usefulness depends on a number of factors related to the learning task and the structure of the notes themselves [15]. A common finding is that note taking takes a toll on cognitive load and can interrupt attention in ways that are often not inconsequential [16-18].

Notes can be private or shared. Shared notes are often found in workgroup situations where individuals can use them to communicate with each other about what different members find to be important and what individuals think other group members should notice. Shared notes are often associated with information artifacts (e.g. marginalia and sticky-notes). The web has offered new opportunities for shared annotation, and many shared annotation systems in which web pages can have notes associated with them have been developed [19, 20]. Again, although web annotation seems like a promising direction for developers [13, 21], studies of web-based annotation systems have shown only marginal improvements in learning, [22, 23]. Shared annotation environments, however, might have the consequence of creating communities of interest [24].

\subsection{Current Study}

In this study we concentrated on how note taking might influence information browsing behavior when participants are seeking information about political candidates in order to make a voting decision. If note taking requires greater cognitive effort that competes with the learning task, then participants who are taking notes should show less effective browsing behavior. On the other hand, if note taking enhances learning, then we should see more effective browsing behavior. We were also interested in how private notes intended for oneself might differ from shared notes intended to be seen by others [25]. Shared notes serve a more public purpose and might require greater thought.

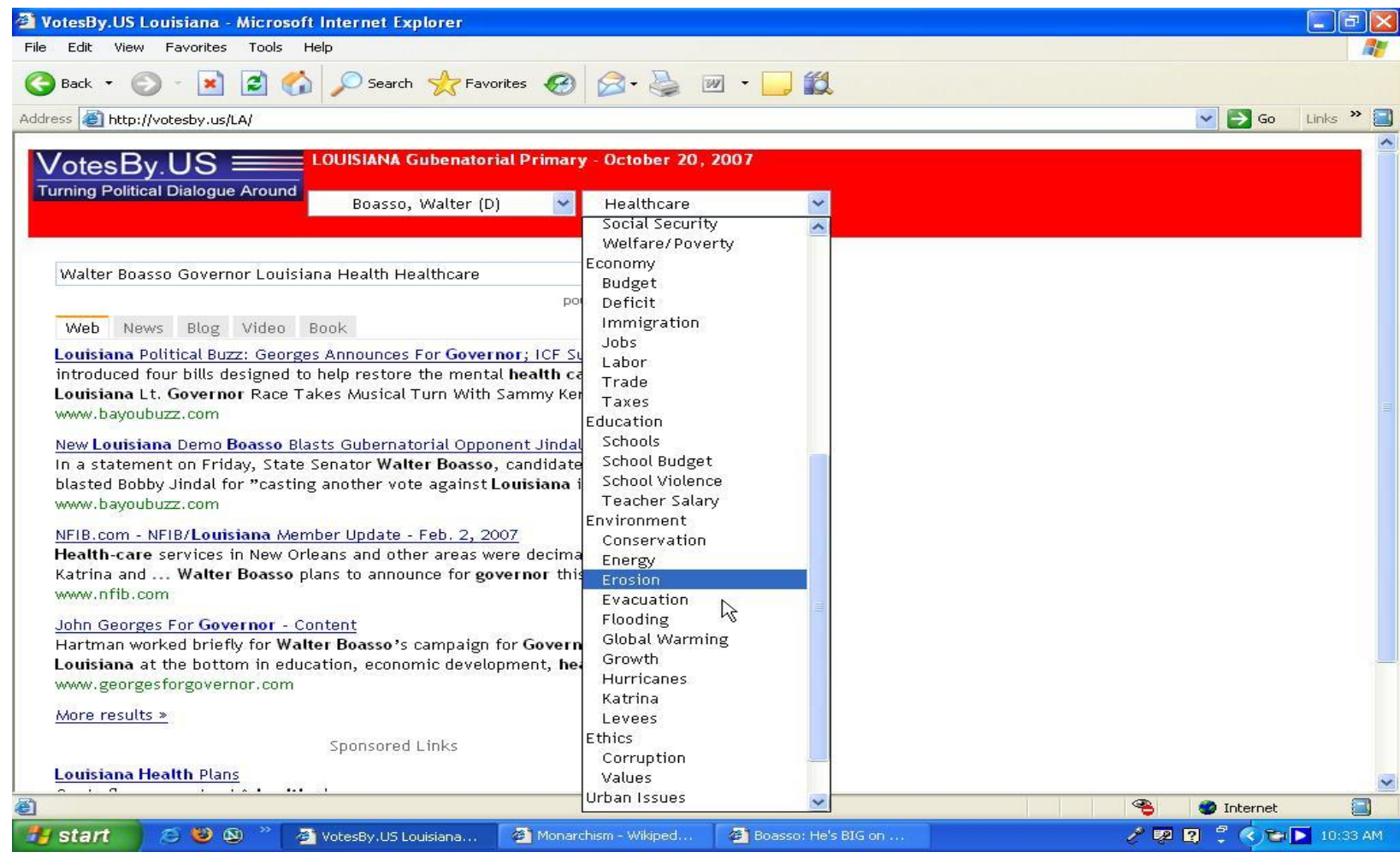

Figure 1: VotesBy.US Portal: The drop-down search interface allows users to select candidates from one list and issues from a second list. Menu selections result in automatic Google searches. Results are returned in s results list with tabbed categories (Web, News, Blog, Video, Book). 
Our primary experimental purpose was to study annotation, however we also added features to a developing voter-browser environment as part of an iterative design exercise. Added features, described below and pictured in Figure 1, were a visible query box, topically organized issue list, and content-tabbed results pages.

\section{Method}

\subsection{Participants}

Thirteen participants were recruited, using information flyers, from areas around Drexel University in Philadelphia, PA. Data was collected from July 05, 2007 to August 07, 2007. Each participant was paid $\$ 35$ for their time.

The age of the participants ranged from 20.0 years to 48.0 years with an average of 33.4 years. One participant each reported high school and 2-year College education whereas nine participants reported 4-year College with the remaining 2 participants reporting an education level of graduate school. Three participants self-reported as "Mixed Race," one participant self-reported as "Native American or Alaskan," another participant selected the category of
"Puerto Rican American (Commonwealth)," and the remaining nine participants selected the category of "White (non-Hispanic)."

Five participants reported being affiliated with the Democratic Party, three as Independents, one participant as affiliated with the Green Party and the rest of the four selected the category of "Other".

Ten out of the thirteen total participants selfreported as having voted in a federal, state, and/or city election in the past. These ten participants further reported that they had cast their vote in the USA general election of 2004. Of the ten participants with positive past electoral voting participation, seven reported that they voted in "most" elections while the remaining three reported voting in "all" elections.

When asked about how often they use the Internet from home, nine participants reported "several times a day," one participant reported "once a day," one participant reported "once every few weeks" and the remaining two participants reported using the Internet less often than every few weeks. With respect to the use of Internet at work, five participants reported "several times a day," three participants reported "once a day," one participant reported "once every few weeks" and four participants reported using the Internet less often than once every few weeks.

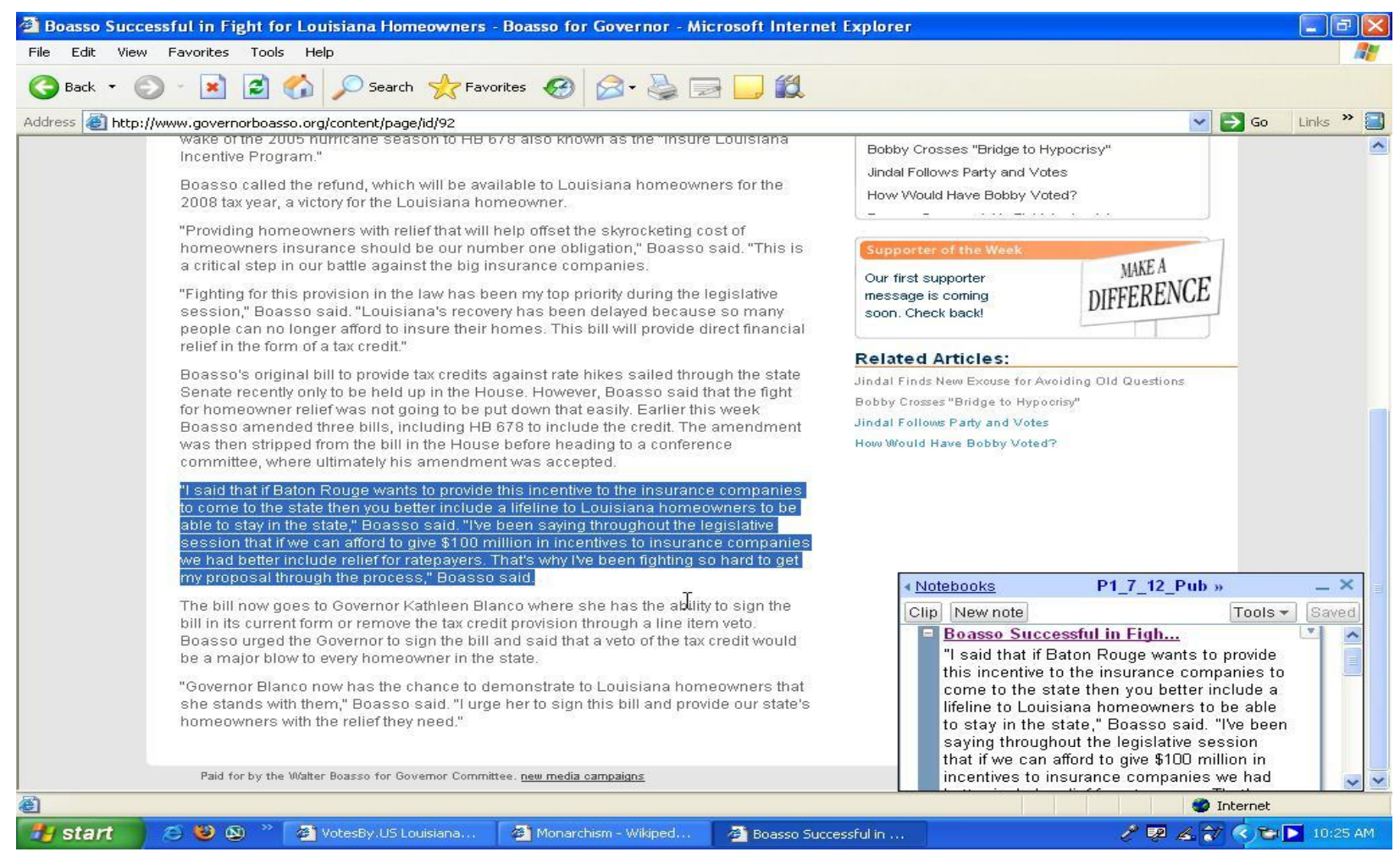

Figure 2. Google Notebook allowed users to make notes. In this example a participant has copied text from a web page that they are browsing into a Notebook shown in the smaller window. 
Regarding the use of Internet for political information seeking, only one participant each reported several times a day and once a day. Five participants reported using the Internet for political information seeking "once or twice a week, "four participants "once every few weeks" and two participants reported using the Internet for looking up political information less often than once every few weeks.

Participants were assigned randomly to one of three note-taking conditions: No Notes, Private Notes, or Shared Notes. Four participants ( 2 female, 2 male) were assigned to No Notes, four participants were assigned to Private Notes, and five participants (1 female, 4 male) were assigned to Shared Notes.

\subsection{Materials and Procedure}

All participants were given a scenario about a mock-voting situation and instructions on how to use a drop-down search interface (Figure 1) to search the internet for campaign information. The scenario asked subjects to imagine that they had just moved to Louisiana where a gubernatorial election was coming up. The participants were informed that there were four candidates for Louisiana Governor: Bobby Jindal, Walter Boasso, John Georges, and Foster Campbell. These were actual candidates in an upcoming election at the time the study was conducted. Participants were told that they were going to "vote for one candidate for the governor of the state of Louisiana" and that they should use the search interface to find out what they needed to know in order to make a choice. Materials that participants' discovered and browsed on the internet were real and

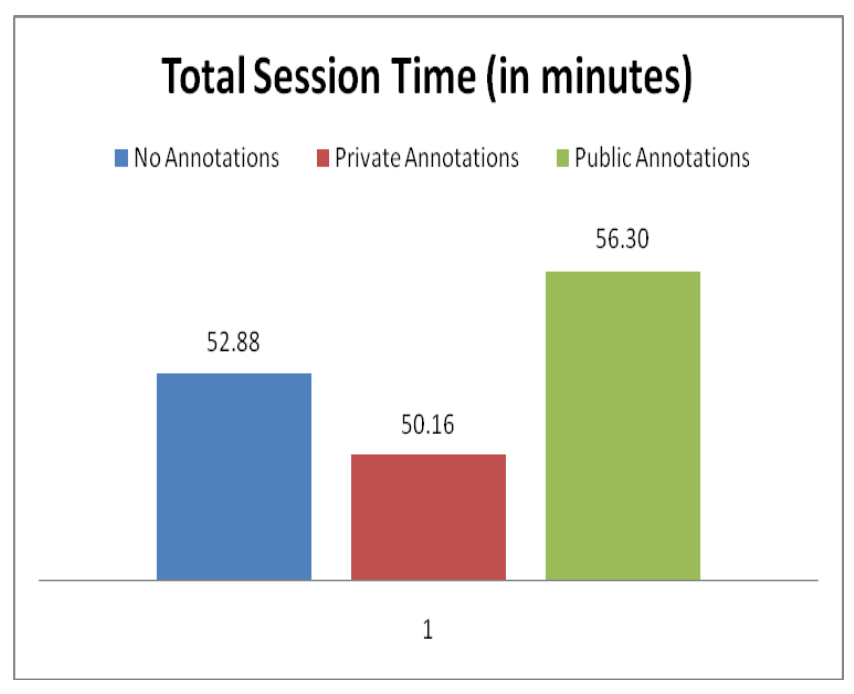

Figure 3. Total Session Time in Minutes. current campaign materials.

Participants in the two annotation conditions were instructed about taking notes with Google Notebook. (Figure 2). Participants in the Shared Notes condition were told that their notes would be available for other users to see when those users were browsing the same materials, whereas participants in the Private Notes condition were told that their notes were for their use only.

In order to search the internet, participants used an interface with two drop-down selection menus, one listing the candidates' names and another listing a set of issues (see Figure 1). Robertson et al. [12] described the initial design of this "drop-down" search interface and showed that it results in more thorough and complete searching and browsing than a free-form query box. Selections from the dropdown lists generated queries which were visible in a query box and which were automatically sent to Google. Selection of a candidate resulted in a search query consisting of that candidate's name and the office (e.g. "Bobby Jindal Governor Louisiana"). Selection of an issue resulted in a search query consisting of the issue keyword (e.g. "taxes"). When menu items were selected from both lists the result was a combined query (e.g. "Bobby Jindal Governor Louisiana taxes").

An AJAX API to Google was utilized to display search results on pages with the following content categorization tabs: Web, News, Blog, Video, and Book. Participants could page through results lists, or look at the results lists under each tab, or open web pages from the results lists.

While carrying out the tasks described in the scenario participants were encouraged to think aloud. Software was used to capture and integrate the search behavior and verbalizations of the each participant. An experimenter remotely tagged the capture file while the participant was searching for information. These tags were adapted from previous studies we conducted on online political information seeking behavior $[12,26]$. Participants were given as long as they wished to search and instructed that they should tell the experimenter when they were ready to vote. After voting, participants were given a recall survey and an exit questionnaire.

\section{Results}

\subsection{Time}

Participants were allowed as much time as they needed to complete the task. They made the choice of when to stop browsing and vote. On average, 
participants spent 53.36 minutes browsing, and there was no significant difference in time spent across the three annotation conditions (see Figure 3).

\subsection{Confidence in the Final Vote}

Participants rated their confidence in their final vote on a Likert scale from 1-5 where higher values signified greater confidence. The average confidence rating was a 2.61, and there was no significant difference in confidence across the three annotation conditions.

\subsection{Searching and Information Browsing}

We conducted an analysis of the screen recordings of participants' activities. Morae Observer ${ }^{\mathrm{TM}}$ was used for the coding of the participant sessions for following events: search queries, website visits, return to the search results, think-aloud comments, making annotations, and reviewing annotations. The resulting screen recordings along with the marker data were analyzed using Morae Manager ${ }^{\mathrm{TM}} 2.0$.

We compared several searching and browsing activities across the three annotation conditions. In each case we conducted an overall ANOVA on the means in the three annotation conditions, a planned comparison of the No Notes condition with the combined annotation conditions, and (if the ANOVA was significant) a post-hoc comparison (Tukey HSD test) of all pairs of means. Dependent measures that we examined in this way were number of search queries, number of websites visited, number of returns to the results list, and number of think-aloud comments made. Figure 4 shows the means for all of these measures across the three annotation conditions.

\subsubsection{Search Queries}

Possible search queries were categorized as being Candidate Name (selecting a candidate name from one of the drop-down lists without selecting an issue), Issue (selecting an issue from one of the drop down lists without selecting a candidate), or Candidate+Issue (selecting a candidate name and an issue to a combined search). Participants made no Issue searches. A within-subjects comparison showed that participants made significantly more Candiate+Issue searches $($ mean $=13.15)$ than Candidate Name searches (mean=4.23), $t(12)=2.65$, $p<.05$. This is consistent with our prior work $[10,11]$ showing that the drop-down interface encourages more complex queries about where candidates stand on various issues.

The number of Candidate Name search queries that participants made differed significantly across the three annotation conditions, with means $=1.7,5.5$, and 5.2 queries per participant for No Notes, Private Notes, and Shared Notes conditions respectively, $F(2,10)=4.64, p<.05$. The contrast test between $N o$ Notes and the combined note taking conditions was significant, $t(10)=-3.05, p<.01)$. Tukey HSD post-hoc comparisons showed that the annotation conditions did not differ from each other, but that both annotation conditions differed from the No Notes condition ( $p<.05$ for No Notes versus Private Notes, and $p<.06$ for No Notes versus Shared Notes).

The number of Candidate+Issue search queries that participants made differed significantly across the three annotation conditions, with means $=21.2$, 14.7, and 5.4 queries per participant for No Notes, Private Notes, and Shared Notes conditions respectively, $F(2,10)=4.10, p<.05$. The contrast test between No Notes and the combined note taking conditions was significant, $t(10)=-2.22, \quad p<.05)$.

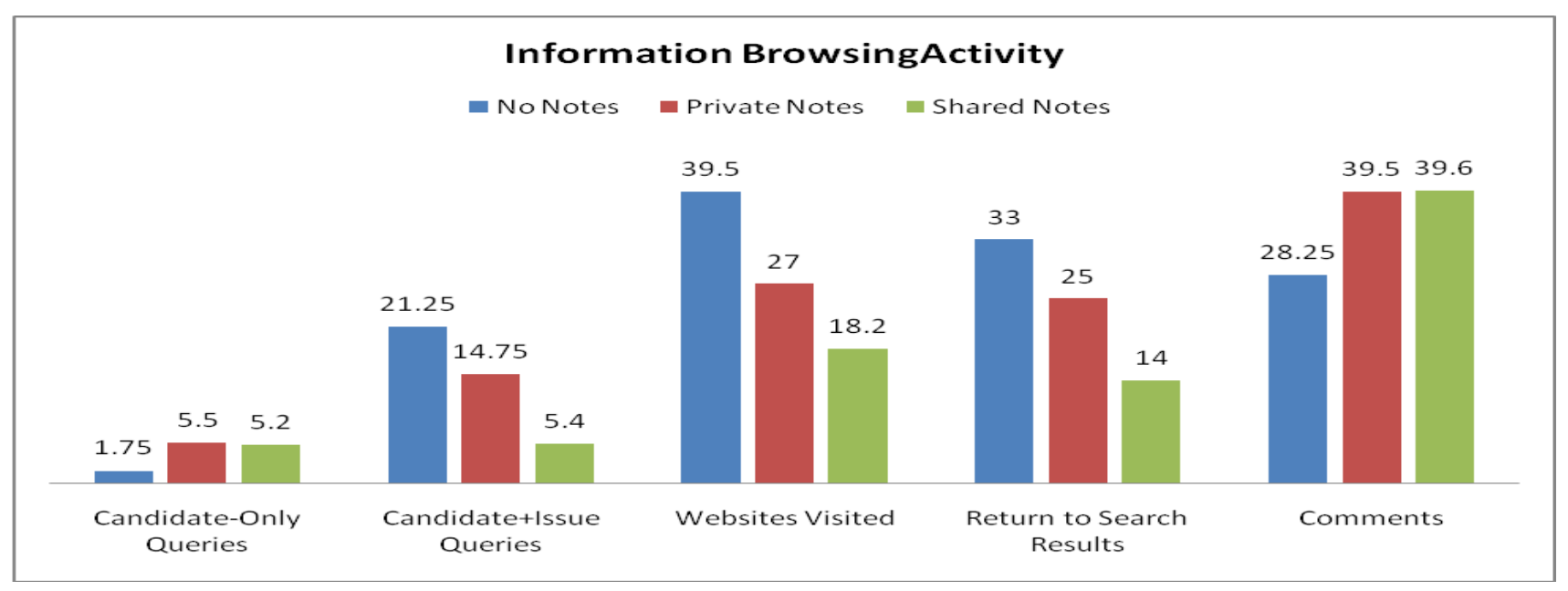

Figure 4. Frequencies of Searching and Browsing Activities the Three Annotation Conditions. 
Tukey HSD post-hoc comparisons showed that the No Notes condition differed significantly from the Shared Notes condition $(p<.05)$.

\subsubsection{Websites Visited}

The number of websites visited decreased across the three annotation conditions, with means $=39.5,27.0$, and 18.2 websites per participant for No Notes, Private Notes, and Shared Notes conditions respectively. The overall trend did not reach significance at the .05 level, but could be considered suggestive with such a small n, $F(2,10)=2.75, p<.11$. The contrast between No Notes and the combined note taking conditions was also suggestive, $t(10)=2.07, p<.07$.

\subsubsection{Returns to Results List}

The number of returns to the results list decreased across the three annotation conditions, with means $=33.0,25.0$, and 14.0 returns per participant for No Notes, Private Notes, and Shared Notes conditions respectively, $\mathrm{F}(2,10)=4.22, \mathrm{p}<.05$. The contrast between No Notes and the combined note taking conditions was significant, $t(10)=2.27, p<.05$. Tukey HSD post-hoc comparisons showed that the No Notes condition differed significantly from the Shared Notes condition $(p<.05)$.

\subsubsection{Comments}

The number of comments appeared to increase when participants were taking notes, with means $=28.2,39.5$, and 39.6 comments per participant for No Notes, Private Notes, and Shared Notes conditions respectively, although this effect was not significant.

\subsubsection{Correlations}

The number of Candiate+Issue queries, the number of returns to the results lists, and the number of websites visited were all highly positively correlated with each other (Table 1). The number of Candidate Name queries was negatively correlated with the number of Candidate+Issue queries, but this is an artifact of the interface (since the usual method of making Candidate +Issue queries was to select a candidate first and then follow it with selections of several issues, which generates a single Candidate Name query for every set of Candiate+Issue queries). The number of Candidate Name queries was also negatively correlated (though not significantly) with number of returns to results and number of websites

\begin{tabular}{|l|l|l|l|}
\hline & $\begin{array}{l}\text { Candidate } \\
\text { + Issue }\end{array}$ & $\begin{array}{l}\text { Returns to } \\
\text { Results }\end{array}$ & $\begin{array}{l}\text { Websites } \\
\text { Visited }\end{array}$ \\
\hline $\begin{array}{l}\text { Candidate } \\
\text { Name }\end{array}$ & $\begin{array}{l}r(13)=-.70 \\
(p<.01)\end{array}$ & $\begin{array}{l}r(13)=-.50 \\
(p<.08)\end{array}$ & $\begin{array}{l}r(13)=-.41 \\
(p<.17)\end{array}$ \\
\hline $\begin{array}{l}\text { Candidate } \\
\text { + Issue }\end{array}$ & & $\begin{array}{l}r(13)=.65 \\
(p<.01)\end{array}$ & $\begin{array}{l}r(13)=.55 \\
(p<.05)\end{array}$ \\
\hline $\begin{array}{l}\text { Returns to } \\
\text { Results }\end{array}$ & & & $\begin{array}{l}r(13)=.94 \\
(p<.001)\end{array}$ \\
\hline
\end{tabular}

Table 1. Correlations between querying and browsing activities.

visited. Though marginal, together these negative correlations suggest that Candidate Name searchers were not as thorough as Candidate+Issue searchers.

Number of comments was positively correlated with both confidence, $r(13)=.56, p<.05$, and session time, $r(13)=.53, p<.06$, although confidence and session time were not correlated with each other.

\subsection{Content of Think-Aloud Comments}

Transcription of the think-aloud comments resulted in 457 individual comments. Following [11, $12]$, the comments were coded into 10 categories by two coders (RV and AJ) independently. Cohen's Kappa for assessing inter-coder reliability was initially 0.62 , which translates to moderate agreement [27]. The coders reconciled differences and eventually assigned each comment to a final category as follows (see Figure 5):

- Goal (3\%): A statement about what the participant plans to do, e.g. "I am going to see if there is anything noteworthy here" OR "I am going to delve into some things in more detail."

- Action (9\%): A statement describing what the participant was doing, e.g. "I am trying to look at the local news on this page" OR "I am looking at his website."

- Question (3\%): An interrogative statement, e.g. "What does he say about war?" OR "Why is Blanco here?"

- Evaluative General (20\%): A general evaluative remark but not related to the ballot item, e.g. "I am going to stay away from blogs" OR "This looks out of date."

- Evaluative about an issue (18\%): Evaluative comment but cannot be determined positive or negative about a political issue, e.g. "He is for single gender classrooms, which I don't know is good or bad." OR "He suggests instituting a tax on oil and gas." 


\section{User Comments}

No Notes Private Notes $\square$ Shared Notes

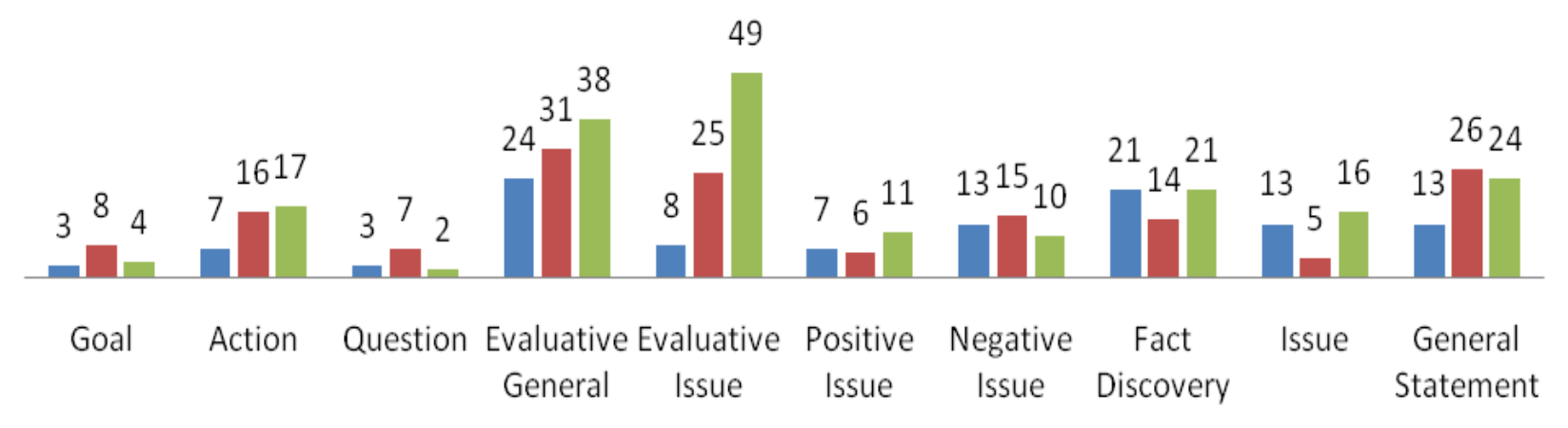

Figure 5: Frequencies of Think Aloud Comment Categories in the Three Annotation Conditions

- Positive about an issue (5\%): A good evaluative comment in support of a political issue, e.g. "I like how he worked for hurricane and stuff" OR "Strikes me better than the other candidate, talks about other important issues".

- Negative about an issue (8\%): A bad evaluative remark about a political issue, e.g. "He voted yes on wire tapping, I don't like that either" OR "He can't even impress me with his own website."

- Fact Discovery (12\%): A statement of a nonevaluative piece of information about one of the candidates, e.g. "It is an open seat, that's what I thought" OR "Oh, he is a state senator."

- Issue (8\%): A non-evaluative statement about a particular political issue, e.g. "I am curious about their stance on Illegal Immigration, but not finding much" OR "He seems to be focused on resolving the crime issue, more so than the others."

- General Statement (14\%): A non-evaluative comment not specifically about a candidate, e.g. "I am new to the state so don't know a lot of stuff" OR "I am beginning to understand this."

By far the largest percentage of comments (51\%) were evaluative in some way. Figure 5 shows the distribution of comments across the three annotation conditions. In general, when there are large discrepancies among the three annotation conditions, they tend to be in the direction of more commenting when taking notes, especially shared notes. The greatest variation across annotation conditions involves the Evaluative General and Evaluative Issue comments. In both cases, note taking increased commenting, and Shared Notes elicited twice as many evaluative comments about issues than Private Notes.

\section{Discussion}

\subsection{Summary}

Our results can be summarized as follows:

- Participants did not take more time when they took notes, which meant that they had to use less time for searching and browsing in the annotation conditions.

- Participants performed more Candidate+Issue searches than simple candidate name searches.

- Participants never searched just on issues.

- Candidate + Issue searches resulted in more activity and exposure to more information.

- Taking notes, especially shared notes, resulted in a reduction in number of searches.

- Taking notes, especially shared notes, resulted in fewer returns to examine results lists.

- Taking notes, especially shared notes, resulted in exposure to less information as evidenced by number of websites visited.

- Taking notes resulted in more reflection on action as evidenced by number of comments.

- Reflection on action, as evidenced by number of comments, increased confidence in the final vote.

- Participants were primarily thinking about evaluative issues while searching and browsing. 
- Taking notes, especially shared notes, increased evaluative reflection.

Taken together, these results show that note taking has a powerful influence on the type of searching and browsing that people do when making a voting decision. The fact that note taking reduces the extent and thoroughness of searching and browsing is perhaps a negative influence. However note taking does seem to increase evaluative thought and so could also be shifting cognitive effort from information foraging and gathering to information analysis and synthesis.

\subsection{Voter-Browser Design}

A major goal of our series of experiments in this area $[12,26,28,29]$ is to develop a browsing tool to help voters using iterative prototyping based on empirical data. In previous research [12], we developed the drop-down interface and demonstrated its efficacy for increasing the depth and complexity of searches beyond the typical candidate-name-only query. In this study we have replicated our finding with regard to increased issue-based searching, and we intended to introduce a new annotation component to the browser. Our results, however, give us pause in suggesting that adding an annotation feature is a good idea.

We also hoped to gain some understanding about how annotation sharing might be integrated into a voter browser. The introduction of sharing moves the application into the realm of a socio-technical system. Even in this impoverished situation where the voters know little about the candidates and issues, and where they do not know who will see their notes, they behaved quite differently when they thought their notes would be shared. How much more of an impact on searching and browsing might there be in "real" situations where the voters are more engaged with the issues and where they are sharing their notes/thoughts with a community of interest? Shared notes have a communicative purpose that private notes do not. Our results suggest that voters wish to share their evaluative analyses. This is a significant "added feature" to the task of gathering information about how to vote. However, this is precisely the added feature on which social networking sites and blogs capitalize, and the use of these sites in political discourse is increasing dramatically.

A second design feature that was added to the drop-down interface in this study was the content category tabs. These tabs organize results into $\mathrm{Web}$, News, Blog, Video, and Book categories (see Figure 1). While we did not concentrate on the tab feature in this article, it is worth noting that participants did not use it much and that some participants even explicitly mentioned that they were going to "stay away from blogs." Reluctance to use the tab feature is yet another indication that searching and browsing in order to make a voting decision is a demanding task from which users do not want many distractions.

We speculate that avoidance of blogs may have to do with the perceived value of political dialog in final decision making. Vatrapu, Robertson, \& Dissanayake [30] have pointed out that political blogs operate as both public spheres and partisan spheres. Blog information could be most useful for forming general impressions or developing opinions over time in social contexts, but less useful for actually deciding something. Again, this is a contrast of deliberation versus decision tasks, and may provide a meaningful caution to designers interested in combining social technologies with decision support tools. On the other hand, many of our participants made considerable use of Wikipedia, another social technology, but one that is perceived as more "objective." Thus, when considering integration of social technologies in a voter-browser, the type of discourse and style of collaborative information management is important.

\subsection{E-Democracy Versus E-Participation?}

When generalized, the issues discussed above raise a larger question of whether there will be important tradeoffs between e-Democracy (involving information gathering and choice making) and eParticipation (involving discourse and social deliberation) technologies. Tradeoffs include design decisions for developers (e.g. Will the addition of a chat feature decrease searching and browsing?), for users (e.g. Will I get more out of using a candidate's social networking site or their website?), and theorists (e.g. Does technology that emphasizes participation negatively impact information 
consumption? Or conversely, does information overload negatively impact civic participation?). While many researchers have noted dramatically increased participation of politicians and voters, especially younger voters, in social networking contexts, we have yet to find out if this will translate into being better informed or into actual voting.

Individuals vote, communities don't. While voting decisions are influenced by others and by one's socially constructed identity and culturally constituted subjectivity, the nature of the secret ballot is such that the individual is the dominant decision maker when the ballot is cast. In previous research [29], we discovered that simply integrating an online ballot with a political information browser was rejected by users possibly because they do not feel that these are similar activities. The success of integrating social technologies with information browsers will depend on the degree to which information sharing and political discourse is considered to be different by nature from information gathering and decision making.

\section{Future Work}

This study serves a second purpose as a pilot study for examining integration of personal and social information management tools with a voterbrowser. In terms of continued development of the drop-down interface (which currently resides on the web at http://www.VotesBy.US), we intend to examine personalization of the drop-down items in future research. We also intend to explore how discourse and deliberation components such as chats and blogs might impact use of the browser. The current results suggest that these technologies will have very significant impacts on browsing behavior, and that the collaboration environment and style of discourse will have an impact on their acceptance and usefulness

With the increased use of social networking tools in this year's election cycle in the United States, we have also been studying users of Facebook's political applications. This is an example of an application that is primarily social and deliberative and secondarily informational.

Finally, we feel that the question of tradeoffs between technologies for e-Democracy and eParticipation is a surprising and important one, and we intend to explore this in more detail as well.

\section{Acknowledgements}

This material is based upon work supported by the National Science Foundation under Grant No. IIS0535036 to the first author. Any opinions, findings and conclusions or recommendations expressed in this material are those of the authors and do not necessarily reflect the views of the National Science Foundation.

\section{References}

[1] L. Raine, J. Horrigan, and M. Cornfield, "The Internet and Campaign 2004", Pew Internet and American Life Project Report, Washington, DC, 2005. Available at http://www.pewinternet.org/pdfs/PIP_2004_Campaign.pdf.

[2] A. P. Williams, and J. C. Tedesco, The Internet Election: Perspectives on the Web in Campaign 2004, Rowman \& Littlefield Publishers, 2006.

[3] A. Smith, and L. Raine, "The Internet and the 2008 election", Pew Internet and American Life Project Report, Pew Research Center, Washington, DC. 2008. Available at: http://www.pewinternet.org/pdfs/PIP_2008_election.pdf

[4] A. Kohut, "Social Networking and Online Videos Take Off: Internet's Broader Role in Campaign 2008", Pew Internet and American Life Project Report, Pew Research Center, Washington, DC, 2008. Available at http://www.pewinternet.org/pdfs/Pew_MediaSources_jan0 8.pdf, 2008.

[5] M. Cornfield, "The Internet and Campaign 2004: A Look Back at the Campaigners", Pew Research Center, Washington, D.C, 2005. Available at http://www.pewinternet.org/files/Cornfield_commentary.pd f

[6] J. Trippi, The Revolution Will Not Be Televised: Democracy, the Internet, and the Overthrow of Everything, Regan Books, 2004.

[7] A. Sullivan, "Barack Obama is Master of the New Facebook Politics", Sunday London Times, May 25, 2008. Available at Times Online: http://www.timesonline.co.uk/tol/comment/columnists/andr ew_sullivan/article3997523.ece.

[8] B. Williams, and G. Gulati, "The Political Impact of Facebook: Evidence from the 2006 Midterm Elections and 2008 Nomination Contest", Politics and Technology Review, vol. 1, pp. 11-21, 2008.

[9] J. Horrigan, K. Garrett, and P. Resnick, "The Internet and Democratic Debate", Pew Internet and American Life Project Report, Washington, DC, 2004. Available at 
http://www.pewinternet.org/pdfs/PIP_Political_Info_Repor t.pdf

[10] S. P. Robertson, "Voter-Centered Design: Toward a Voter Decision Support System", ACM Transactions on Computer-Human Interaction (TOCHI), vol. 12, no. 2, pp. 263-292, 2005.

[11] S. P. Robertson, "Design Research in Digital Government: A Query Prosthesis for Voters", Proceedings of dg.o2008: 9th Annual Conference on Digital Government Research, New York: ACM Press, 2008.

[12] S. P. Robertson, C. E. Wania, G. Abraham, and S.J. Park, "Drop-Down Democracy: Internet Portal Design Influences Voters' Search Strategies", Proceedings of the $41^{\text {st }}$ Annual Hawaii International Conference on System Sciences, 2008.

[13] C. C. Marshall, "Annotation: From Paper Books to the Digital Library", Proceedings of the Second ACM International Conference on Digital Libraries, pp. 131-140, 1997.

[14] L. Denoue, and L. Vignollet, "Personal Information Organization Using Web Annotations", Proceedings of the WebNet 2001 World Conference on the WWW and Internet, pp. 279-283, 2001.

[15] L. B. Igo, K. A. Kiewra, and R. Bruning, "Individual Differences and Intervention Flaws: A Sequential Explanatory Study of College Students' Copy-and-Paste Note Taking", Journal of Mixed Methods Research, vol. 2, no. 2, pp. 149-168, 2008.

[16] R. E. Mayer, and R. Moreno, "Nine Ways to Reduce Cognitive Load in Multimedia Learning", Educational Psychologist, vol. 38, no. 1, pp. 43-52, 2003.

[17] T. Olive, R. T. Kellogg, and A. Piolat, "The TripleTask Technique for Studying the Process of Writing", In T. Olive and C. Levy, eds., Contemporary Tools and Techniques for Studying Writing, pp. 31-59, Dordrecht: Kluwer Academic Publishers, 2001.

[18] A. Piolat, T. Olive, and R. T. Kellogg, "Cognitive Effort During Note Taking", Applied Cognitive Psychology, vol. 19, no. 3, pp. 291-312, 2005.

[19] I. Glover, Z. Xu, and G. Hardaker, "Online Annotation-Research and Practices", Computers \& Education, vol. 49, no. 4, pp. 1308-1320, 2007.

[20] P. L. Rau, S. H. Chen, and Y. T. Chin, "Developing Web Annotation Tools for Learners and Instructors", Interacting with Computers, vol. 16, no. 2, pp. 163-181, 2004.
[21] X. Fu, T. Ciszek, G. Marchionini, and P. Solomon, "Annotating the Web: An Exploratory Study of Web Users' Needs for Personal Annotation Tools", Proceedings of the 68th Annual Meeting of the American Society for Information Science \& Technology, 42. Charlotte, NC, 2005.

[22] W. Y. Hwang, C. Y. Wang, and M. Sharples, "A Study of Multimedia Annotation of Web-Based Materials", Computers \& Education, vol. 48, no. 4, pp. 680-699, 2007.

[23] P. Nokelainen, M. Miettinen, J. Kurhila, P. Floreen, and H. Tirri, "A Shared Document-Based Annotation Tool to Support Learner-Centred Collaborative Learning", British Journal of Educational Technology, vol. 36, no. 5, pp. 757-770, 2005.

[24] J. J. Cadiz, A. Gupta, and J. Grudin, "Using Web Annotations for Asynchronous Collaboration Around Documents", Proceedings of the 2000 ACM Conference on Computer Supported Cooperative Work, pp. 309-318, 2000 .

[25] C. C. Marshall, and A. J. B. Brush, "Exploring the Relationship Between Personal and Public Annotations", Proceedings of the 2004 Joint ACM/IEEE Conference on Digital Libraries, pp. 349-357, 2004.

[26] S. P. Robertson, C. E. Wania, and S. J. Park, "An Observational Study of Voters on the Internet", Proceedings of the 40th Annual Hawaii International Conference on System Sciences, 2007.

[27] J. Landis, and G. Koch, "The Measurement of Observer Agreement for Categorical Data", Biometrics, vol. 33, no. 1, pp. 159-174, 1977.

[28] S. P. Robertson, "Digital Deliberation: Searching and Deciding About How to Vote", Proceedings of dg.02006: 7th Annual Conference on Digital Government Research, New York: ACM Press, 2006.

[29] S. P. Robertson, P. Achananuparp, J. L. Goldman, S.J. Park, N. Zhou, and M. J. Clare, "Voting and Political Information Gathering on Paper and Online", Extended Abstracts of CHI '05: Human Factors in Computing Systems. New York: ACM Press, pp. 1753-1756, 2005.

[30] R. Vatrapu, S. P. Robertson, and W. Dissanayake, "Are Political Weblogs Public Spheres or Partisan Spheres?", International Reports on Socio-Informatics, in press. 